\title{
ISOLATION, CULTIVATION AND CHARACTERIZATION OF QUAIL PRIMORDIAL GERM CELLS
}

\section{N.A. VOLKOVA, V.A. BAGIROV, E.K. TOMGOROVA, A.N. VETOKH, L.A. VOLKOVA, N.A. ZINOVIEVA}

\author{
L.K. Ernst All-Russian Research Institute of Animal Husbandry, Federal Agency of Scientific Organizations, 60, pos \\ Dubrovitsy, Podolsk District, Moscow Province, 142132 Russia, e-mail natavolkova@inbox.ru \\ ORCID: \\ Volkova N.A. orcid.org/0000-0001-7191-3550 \\ Bagirov V.A. orcid.org/0000-0001-8385-2433 \\ Vetokh A.N. orcid.org/0000-0002-2865-5960 \\ Tomgorova E.K. orcid.org/0000-0001-5398-8815 \\ Volkova L.A. orcid.org/0000-0002-9407-3686
}

The authors declare no conflict of interests

Acknowledgements:

Supported financially by Russian Science Foundation (grant № 16-16-04104)

Received December 30, 2016

Abstract

The use of avian primordial germ cells (PGCs) for production of chimeric and transgenic poultry is regarded as an alternative way to traditional methods of selection and transgenesis. This approach involves the introduction of donor primordial germ cells in the dorsal aorta of the recipient embryo during their migration from blood to gonads. In case of recipient embryo gonads colonization by donor PGCs, the further differentiation of donor cells into mature germ cells becomes possible, for both males and females. A key factor for the effectiveness of this manipulation is obtaining of a pure population of embryonic cells. In this regard, the development of effective methods for isolation and maintenance of PGCs in culture is important. Our research was aimed at the improvement of methodical approaches for isolation and cultivation of quail PGCs. This type of cells was isolated and characterized. Five- to six-day embryos were used for obtaining PGCs culture. Isolation of PGCs from quail embryos was performed using two methodological approaches - mechanical dissociation and enzymatic treatment. Trypsin solution at concentration from $0.05 \%$ to $0.25 \%$ was used as proteolytic enzyme for enzymatic treatment. In order to obtain the most pure populations of PGCs, unequal ability to adhesion of different types of cells was taken into account. It was found that enzymatic treatment with $0.05 \%$ trypsin is an effective method for embryos disaggregation preserving significant proportion of viability (94\%) of fetal cells. Separation of different cell types based on their different ability to adhesion allows obtaining PGCs culture maximally purified from other cell types. Moreover, single embryo fibroblasts, remaining in the PGCs cell suspension after separation from the other cell types are used as a feeder layer to which PGCs are attached at the subsequent cultivation. It was shown that own primary embryonic fibroblasts are optimal as a feeder layer for short-term PGCs culturing as compared to the use of STO cells and cultured embryonic fibroblasts. If using the growth medium based on DMEM with high glucose level $(4.5 \mathrm{~g} / \mathrm{l})$ supplemented with $20 \%$ fetal bovine serum, $2 \mathrm{mM}$ glutamine, $10^{-6} \mathrm{mM}$ 2-mercaptoethanol, $2 \mathrm{ng} / \mathrm{ml}$ LIF (leukemia inhibitory factor), $10 \mathrm{mM}$ essential amino acids (MEM), the antibiotic gentamicin $(50 \mathrm{ug} / \mathrm{ml})$ the attachment of PGCs to the feeder layer was observed at day 1 to 2 of cultivation forming colonies at day 3 to 4 . The presence of primordial germ cell colonies was confirmed by immunohistochemistry using specific primary antibodies to SSEA-1 (stage-specific embryonic antigen-1).

Keywords: primordial germ cells, quail, embryos

The production of transgenic and chimeric individuals based on primordial germ cells (PGC) is recognized as one of the promising areas of modern biotechnology, which are discussed as an alternative to traditional methods of genome selection and modification [1-5]. The use of this type of cells in selection and biotechnological programs opens wide opportunities for directed genome modification and the reconstruction of valuable breeds and lines preserved in cryobank conditions [6-12]. Peculiarities of biology of agricultural poultry allow us to consider PGC as a promising genetic material. The development of bird embryos outside 
the female organism greatly facilitates the manipulations associated with the isolation of PGC from donor embryos and their transplantation into recipient embryos.

Primordial embryonic cells are the precursors of the germ cells. They are pluripotent, that is, in the process of embryogenesis they can differentiate into both male and female germ cells, which greatly expands the possibilities of realizing their potential when creating transgenic and chimeric individuals with given properties. The technology for obtaining such individuals involves the transplantation of donor cells into the gonads of recipient embryos [13, 14]. Subsequently, these individuals can be used as "bioreactors", which produce in the genital organs mature donor cells (sperms, ovules) serving as genetic material for obtaining descendants with given properties. When recreating the breeds and lines of agricultural birds, the use of this approach is more preferable in comparison to frozen-thawed spermatozoa, since it makes it possible to support the gene pool studs by male and female genetic material.

One of the key factors ensuring the effectiveness of the described technology is the production of a culture of PGC which is maximally purified from other types of embryonic cells. Much of the research was performed on chickens [1520]. The identification and characterization of PGC of other types of agricultural poultry is topical.

Here, we reported the results of isolation and characterization of the quails PGC. It was shown for the first time that the preliminary removal of other cell types, in particular the largest population of embryonic fibroblasts, provides for a high purity of the quail PGC culture. The remaining fibroblasts form a feeder layer that has optimal properties for culturing the PGC as compared to other types of feeder layers.

The aim of the work was to optimize the methods of isolation and cultivation of primordial germ quail cells, as a step in development of technology for obtaining individuals with specified properties.

Tchnique. Primordial germ cells were isolated from 5-day-old quail embryos (Coturnix coturnix) of Estonian breed. For disaggregation of embryos, we used two approaches, i.e. mechanical cell dissociation and enzymatic treatment.

In mechanical dissociation, embryos were ground and pipetted for $5 \mathrm{~min}$ in DMEM (Dulbecco's Modified Eagle's Medium). In the enzymatic treatment, embryos were transferred to physiological solution supplemented with antibiotic-antimycotic, and homogenized. The resulting cell suspension was centrifuged for $5 \mathrm{~min}$ at $200 \mathrm{~g}$. DMEM preheated to $37^{\circ} \mathrm{C}$ was added to the precipitate, pipetted and centrifuged to separate the cells. Trypsin $(0.05,0.10$, 0.15 and $0.25 \%$ ) heated to $37{ }^{\circ} \mathrm{C}$ was added to the precipitate and the cells were intensively pipetted for 5-10 min.

To increase the proportion of PGC in the resulting suspension, different cell types were separated by their capability of adhesion. A series of experiments was performed (in 3 replicates) with short-term cell culture. The proportion of PGC identified by staining for alkaline phosphatase was calculated.

DMEM HG (Invitrogen, USA) with $4.5 \mathrm{~g} / 1$ glucose supplemented with fetal bovine serum $(20 \%)$, glutamine $(2 \mathrm{mM}), 2$-mercaptoethanol $\left(10^{-6} \mathrm{mM}\right)$, LIF (leukemia inhibitory factor, $2 \mathrm{ng} / \mathrm{ml}$ ), essential amino acids (MEM, Minimum Essential Medium, $10 \mathrm{mM})$, antibiotic gentamycin $(50 \mu \mathrm{g} / \mathrm{ml})$ was a growth medium in PGC culture. Cells were removed from the substrate with a $0.25 \%$ trypsin solution.

To prepare feeder layers, the cells, after reaching $90 \%$ monolayer, were exposed for 3 hours to mitomycin C (Sigma, USA), $30 \mu \mathrm{g} / \mathrm{ml}$ final concentration, washed thrice with Hanks solution (PanEko, Russia) and used for PGC culture.

Morphology of freshly isolated quail embryonic cells was studied under 
a phase contrast microscope (Nikon, Japan).

Cultured PGC were identified by immunohistochemical and histochemical staining. The cells were fixed for $10 \mathrm{~min}$ with chilled methanol $\left(-20^{\circ} \mathrm{C}\right)$. The immunohistochemical study was performed with the avidin-biotin test system (Vector Laboratories, USA) [21]. Anti-SSEA-1 (stage-sPGCific embryonic antigen-1) served as the first antibodies. The antigen-antibody complex was detected by peroxidase with 3,3-diaminobenzidine tetrachlorate (DAB) (Vector Laboratories, USA). A BCIP/NBT kit (5-bromo-4-chloro-3-indolphosphate and nitrosine tetrazolium, Vector Laboratories, USA) was used in staining for alkaline phosphatase.

Results. Mechanical dissociation of quail embryos produced separate cells and their groups (Fig. 1, A), while enzymatic treatment (see Fig. 1, B) resulted in cell suspension consisting mainly of isolated cells. The cells practically did not aggregate. Single cell groups were detected only for low trypsin concentrations $(0.05$ and $0.10 \%)$. Their proportion did not exceed $0.2 \%$.
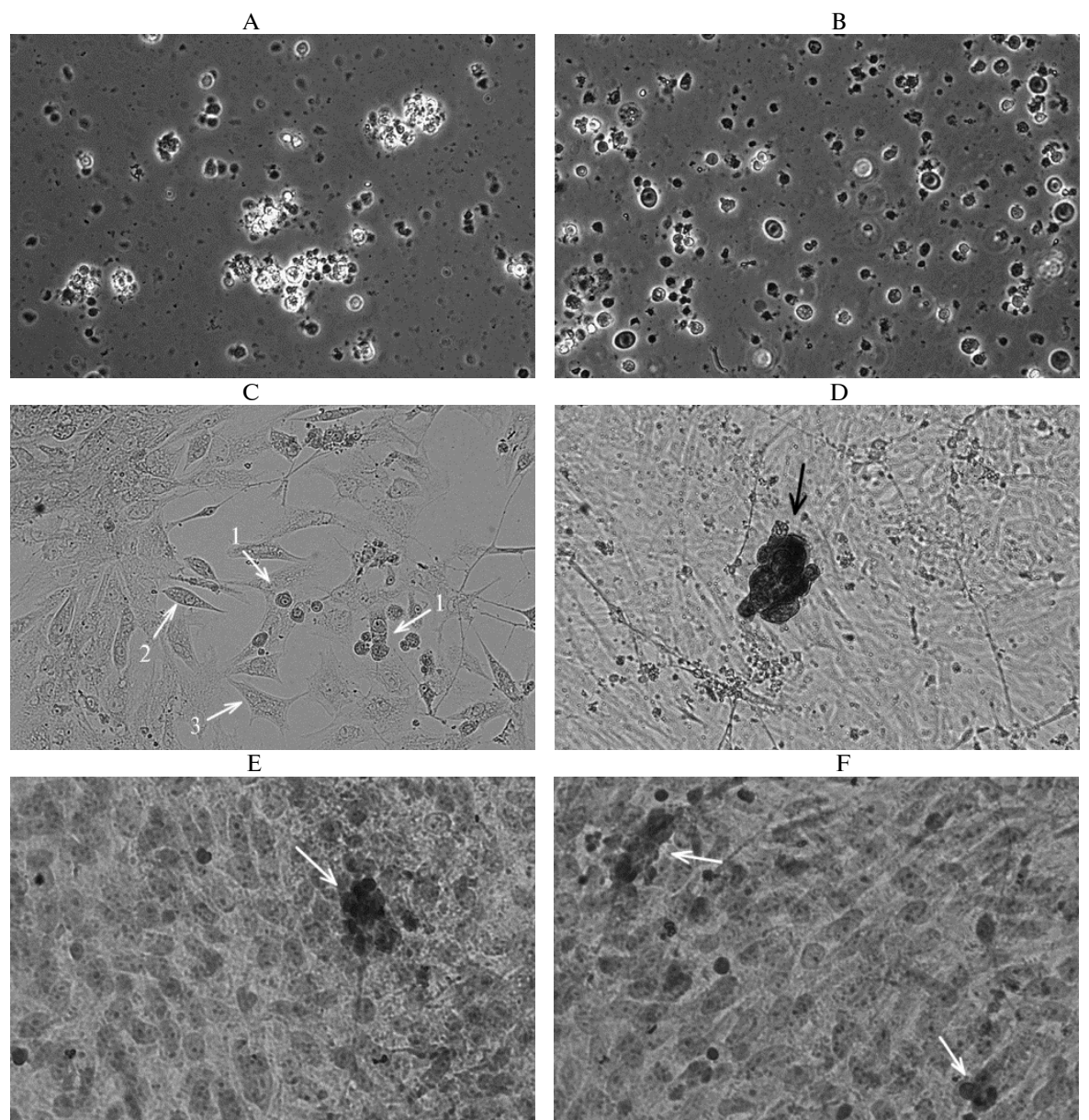

Fig. 1. Primordial germ cells (PGC) obtained from embryos of quails (Coturnix coturnix) of Estonian breed by different dissociation methods: A - suspension of embryonic cells after mechanical dissociation, small conglomerates of cells are seen (native preparation); B - suspension of embryonic cells during enzymatic treatment, isolated cells are seen (native preparation); C -2 -day culture, PGC (1), fibroblasts (2), epithelio-like cells (3) are seen (native preparation); D - 6-day culture, histochemical staining for alkaline phosphatase, arrow marks a colored colony of PGC; E - 4-day culture, immunohistochemical staining for SSEA-1 (stage-specific embryonic antigen-1), arrow marks a PGC colony; F - 4-day culture, absence of specific immunohistochemical staining for SSEA-1 expression in the control (without anti-SSEA-1), arrows mark the PGC colonies. Phasecontrast (A, B) and light (C-F) microscopy (Nikon, Japan), $\times 400$. 
However, the yield of living cells was 4-25\% (depending on the concentration of the trypsin solution) less than in the case of mechanical dissociation, which was associated with the toxic effect of the enzyme on the cells (Fig. 2).

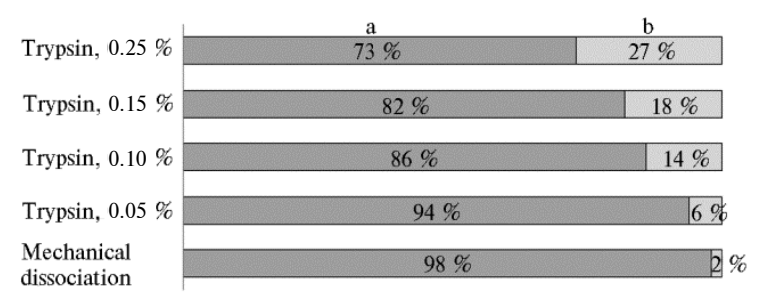

Fig. 2. The proportion of live (a) and dead (b) primordial germ cells from Estonian quail (Coturnix coturnix) embryos produced by mechanical dissociation and trypsinization.

Thus, in trypsinization, the maximum yield of living cells (94\%) was achieved using the minimum enzyme concentration (0.05\%), which was optimal to produce isolated embryonic quail cells while maintaining the high viability of the cell suspension.

The suspension of embryonic cells resulted from trypsinization was plated onto culture dishes. During 1 hour, a significant portion of embryonic fibroblasts were attached to the plastics. After 24 hours, these cells flattened and began to divide. The most PGC, which had the appearance of rounded formations, was in suspension, and only a few were attached to spreading embryonic fibroblasts, using them as a feeder layer. On the day 1 (see Fig., B), the PGC were attached to the feeder layer and acquired a spherical shape.

In the resulting cell population, several types of cells were identified. Numerous groups consisted of embryonic fibroblasts, epithelioide cells and PGC. PGC was characterized by a rounded shape, epithelioide cells were irregular in shape and had large nucleus, fibroblasts were spindle-shaped (see Fig., B).

To maximize the purification of the PGC population, we applied the method based on the unequal adhesive capacities of different cell types. After the embryonic quail cells were primary cultured for 1 hour, the supernatant with non-attached cells was removed and transferred onto fresh Petri dishes to continue culturing. The embryonic fibroblasts present in the suspension after collection of the culture medium served as the feeder layer on which the PGC were attached. After 1 hour, the supernatant was again removed for further culturing. After a three times repeated procedure, the proportion of PGC in the suspension increased to $79 \%$.

Isolated quail PGC were added onto STO (transplanted mouse embryonic fibroblasts) cells, primary embryonic quail fibroblasts, chick embryonic fibroblasts which served as the feeder layers, or onto plates with $0.2 \%$ gelatin. The best results were obtained with primary embryonic quail fibroblasts (Table).

Efficiency of cultivation of primordial germ cells (PGS) of quails (Coturnix coturnix) depending on the feeder layer

\begin{tabular}{l|c|c}
\hline \multicolumn{1}{c|}{ Feeder layer } & $\begin{array}{l}\text { Attaching to the } \\
\text { feeder layer }\end{array}$ & Colony formation \\
\hline STO cell line & On days 1 to 2 & On days 4 to 5 \\
Embryonic fibroblasts of chickens & On days 1 to 2 & On day 4 \\
Primary embryonic quail fibroblasts & On days 1 to 2 & On day 3 \\
\hline N o t e. STO - cell line of transplanted mouse embryonic fibroblasts. & \\
\hline
\end{tabular}

On days 3-4 of the culture, PGC formed colonies the presence of which was confirmed by expression of stem cell markers, the alkaline phosphatase (see Fig., D) and the protein SSEA-1 (see Fig., E, F).

So, in quails, the uniformity of primary germ cells (PGC) culture depends on the method used for their separation from other cell types and the feeder layer. Separation of cells by adhesion ability allows the maximum purification of the PGC culture from other cells, in particular from embryonic fibroblasts. Single embryonic fibroblasts, remaining in the cell suspension, serve as the feeder layer during a subsequent cultivation on which the PGC are attached. 
PGC culturing on the feeder layers with a suitable growth medium allows to obtain PGC colonies on days 3 and 4. Optimum feeder layer for quail PGC culture is formed from native embryonic fibroblasts.

\section{R E F E R E N C E S}

1. Petitte J.N., Karagenc L., Ginsburg M. The origin of the avian germ line and transgenesis in birds. Poultry Sci., 1997, 76: 1084-1092 (doi: 10.1093/ps/76.8.1084).

2. Ginsburg M. Primordial germ cell development in avians. Poultry Sci., 1997, 76: 91-95 (doi: 10.1093/ps/76.1.91).

3. Naito M., Tajima A., Tagami T., Yasuda Y., Kuwana T. Preservation of chick primordial germ cells in liquid nitrogen and subsequent production of viable offspring. Journal of Reproduction and Fertility, 1994, 102: 321-325 (doi: 10.1530/jrf.0.1020321).

4. N a it o M., Harumi T., $\mathrm{Kuw}$ an a T. Long term in vitro culture of chicken primordial germ cells isolated from embryonic blood and incorporation into germline of recipient embryo. J. Poult. Sci., 2010, 47: 57-64 (doi: 10.2141/jpsa.009058).

5. Nakamura Y., Usui F., Miyahara D., Mori T., Ono T., Takeda K., Niras a w a K., Kaga mi H., Taga mi T. Efficient system for preservation and regeneration of genetic resources in chicken: concurrent storage of primordial germ cells and live animals from early embryos of a rare indigenous fowl (Gifujidori). Reprod. Fert. Develop., 2010, 22: 1237-1246 (doi: 10.1071/RD10056).

6. Kuwana T., Kawashima T., Naito M., Yamashita H., Matsuzaki M., Takano T. Conservation of a threatened indigenous fowl (Kureko dori) using the germline chimeras transplanted from primordial germ cells. J. Poult. Sci., 2006, 43: 60-66 (doi: 10.2141/jpsa.43.60).

7. Park T.S., H ong Y.H., K w o n S.C., Li m J.M., H a n J.Y. Birth of germline chimeras by transfer of chicken embryonic germ (EG) cells into recipient embryos. Mol. Reprod. Dev., 2003, 65: 389-395 (doi: 10.1002/mrd.10304).

8. Chojnacka-Puchta L., Kasperczyk K., Płucienniczak G., Sawicka D., $\mathrm{Bednarczyk}$ M. Primordial germ cells (PGCs) as a tool for creating transgenic chickens. Pol. J. Vet. Sci., 2012, 15(1): 181-188 (doi: 10.2478/v10181-011-0132-6).

9. Hong Y.H., M o on Y.K., J e ong D.K., Han J.Y. Improved transfection efficiency of chicken gonadal primordial germ cells for the production of transgenic poultry. Transgenic Res., 1998, 7(4): 247-252 (doi: 10.1023/A:1008861826681).

10. H a n J.Y. Germ cells and transgenesis in chickens. Comparative Immunology, Microbiology and Infectious Diseases, 2009, 32: 61-80 (doi: 10.1016/j.cimid.2007.11.010).

11. Ty a ck S.G., Je nkins K.A., O'Neil T.E., Wise T.G., Morris K.R., B ruce M.P., McLeod S., Wade A.J., McKay J., Moore R.J., Schat K.A., Lowenthal J.W., D ora n T.J. A new method for producing transgenic birds via direct in vivo transfection of primordial germ cells. Transgenic Res., 2013, 22(6): 1257-1264 (doi: 10.1007/s11248-013-9727-2).

12. D'Cost a S., Pardue S.L., Pe tit te J.N. Comparative development of avian primordial germ cells and production of germ line chimeras. Avian Poult. Biol. Rev., 2001, 12(4): 151-168 (doi: 10.3184/147020601783698477).

13. Kang S.J., Cho i J.W., K im S.Y., Park K.J., K im T.M., Le e Y.M., Ki m H., Lim J.M., H a n J.Y. Reproduction of wild birds via interspecies germ cell transplantation. Biol. Reprod., 2008, 79(5): 931-937 (doi: 10.1095/biolreprod.108.069989).

14. Wernery U., Liu C., Baskar V., Guerineche Z., Khazanehdari K.A., $\mathrm{S}$ a 1 e e $\mathrm{m}$ S., K inne J., We rne ry R., Griffi n D.K., C h a ng I.K. Primordial germ cell-mediated chimera technology produces viable pure-line Houbara bustard offspring: potential for repopulating an endangered species. PLoS ONE, 2010, 5: e15824 (doi: 10.1371/journal.pone.0015824).

15. Yamamoto Y., Usui F., Nakamura Y., Ito Y., Tagami T., Nirasawa K., Matsubara Y., Ono T., Kagami H. A novel method to isolate primordial germ cells and its use for the generation of germlinechimeras in chicken. Biol. Reprod., 2007, 77(1): 115119 (doi: 10.1095/biolreprod.107.061200).

16. Mozdziak P.E., Angerman-Stewart J., Rushton B., Pardue S.L., Petitte J.N. Isolation of chicken primordial germ cells using fluorescence-activated cell sorting. Poultry Sci., 2005, 84: 594-600 (doi: 10.1093/ps/84.4.594).

17. O is h i I. Improvement of transfection efficiency in cultured chicken primordial germ cells by percoll density gradient centrifugation. Biosci. Biotech. Bioch., 2010, 74(12): 2426-2430 (doi: 10.1271/bbb.100464).

18. van de Lavoir M.C., Diamond J.H., Leighton P.A., Mather-Love C., Heyer B.S., Bradshaw R., Kerchner A., Hooi L.T., Gessaro T.M., Swanberg S.E., Delany M.E., Etches R.J. Germline transmission of genetically modified 
primordial germ cells. Nature, 2006, 44: 766-769 (doi: 10.1038/nature04831).

19. M a c donald J., Glover J.D., Taylor L., S ang H.M., M c Grew M.J. Characterisation and germline transmission of cultured avian primordial germ cells. PLoS ONE, 2010, 5: e15518 (doi: 10.1371/journal.pone.0015518).

20. Tomgorova E.K., Volkova N.A., Volkova L.A., F is in in V.I., Z inovi e $\mathrm{v}$ a N.A. Isolation and characteristics of primordial germ cells in chicken. Agricultural Biology, 2012, 6: 61-65 (doi: 10.15389/agrobiology.2012.6.61eng) (in Engl.)

21. Mikroskopicheskaya tekhnika /Pod redaktsiei D.S. Sarkizova, Yu.P. Perova [Microscopy technique. D.S. Sarkizov, Yu.P. Petrov (eds.)]. Moscow, 1996 (in Russ.). 